\title{
L'imaginaire des apocalypses, textes rassemblés, présentés et édités par Jean Burgos
}

\section{G. Matteo Roccati}

\section{Q OpenEdition}

10 Journals

\section{Édition électronique}

URL : http://journals.openedition.org/studifrancesi/34272

DOI : $10.4000 /$ studifrancesi.34272

ISSN : 2421-5856

Éditeur

Rosenberg \& Sellier

\section{Édition imprimée}

Date de publication : 1 novembre 2005

Pagination : 388-387

ISSN : 0039-2944

\section{Référence électronique}

G. Matteo Roccati, «L'imaginaire des apocalypses, textes rassemblés, présentés et édités par Jean Burgos », Studi Francesi [En ligne], 146 (XLIX | II) | 2005, mis en ligne le 30 novembre 2015, consulté le 20 avril 2021. URL : http://journals.openedition.org/studifrancesi/34272 ; DOI : https://doi.org/ 10.4000/studifrancesi.34272

Ce document a été généré automatiquement le 20 avril 2021.

\section{(c)}

Studi Francesi è distribuita con Licenza Creative Commons Attribuzione - Non commerciale - Non opere derivate 4.0 Internazionale. 


\title{
L'imaginaire des apocalypses, textes rassemblés, présentés et édités par Jean Burgos
}

\author{
G. Matteo Roccati
}

\section{RÉFÉRENCE}

L'imaginaire des apocalypses, textes rassemblés, présentés et édités par Jean BURGos,

Paris-Caen, Lettres modernes Minard («Bibliothèque Circé», 4), 2003; pp. 262

1 Ce recueil collectif, qui «se veut représentatif des travaux de recherche sur l'Imaginaire conduits par Jean Burgos à l'Université de Savoie» (p. 4), s'étend sur un champ très large: du premier article, Voyage aux sources judaïques de l'Imaginaire apocalyptique: introduction à l'Imaginaire des apocalypses, par Michel BLANC (pp. 9-54), jusqu'à la culture russe, la psychopathologie et Olivier Messiaen, en passant par Dürer et les théosophes J.H. Jung-Stilling (1740-1817) et L.C. de Saint-Martin (1743-1803). Quelques contributions concernent la culture médiévale, elles sont accompagnées de très belles reproductions.

Philippe ABADIE, L'Agneau et le dragon - l'univers symbolique de l'apocalypse johannique et sa représentation dans la Tenture d'Angers, pp. 55-88. Etude des scènes de cette tapisserie d'apparat, réalisée pour Louis $\mathrm{I}^{\text {er }}$ d'Anjou, sans doute achevée en 1382.

Jean-Pierre PERROT, La mise en scène de l'Apocalypse au Moyen Age: «Le Mystère du Jour du Jugement» - espace théâtral et espace intérieur, pp. 113-142. Le mystère est conservé dans le ms. Besançon, B.m. 579, datable de 1340-1350, comportant quatre-vingt-huit miniatures qui «peuvent être considérées comme autant d'«images» d'une représentation» (p. 115). L'article analyse précisément l'espace scénique, exemple de théâtre «en rond», dans le but de dégager «de quelle sorte d'espace intérieur il est la projection» (p. 117): les relations entre les différents lieux sont analysées à l'aide des modèles du carré et de l'hexagone logiques, ainsi que du mandala. 
4 Laurence RIVIÈRE CIAVALDINI, Des fénêtres ouvertes sur l'Imaginaire du prince: étude de quelques miniatures de l'«Apocalypse des ducs de Savoie», pp. 143-161. Les images examinées appartiennent à un cycle de quatre-vingt-dix-sept enluminures, peintes au cours du $\mathrm{XV}^{\mathrm{e}}$ siècle (ms. Escurial E. Vitr. V). Elles révèlent les exigences et les motivations des commanditaires, Amédée VIII et Charles I ${ }^{\text {er: }}$ l'imaginaire de l'Apocalypse est conçu comme «combat flamboyant» sous le premier, "parcours édifiant» (p. 160) au temps du second. 